\title{
Papers
}

\section{Doctors' communication of trust, care, and respect in breast cancer: qualitative study}

Emma Burkitt Wright, Christopher Holcombe, Peter Salmon

\begin{abstract}
Objective To determine how patients with breast cancer want their doctors to communicate with them.

Design Qualitative study.

Setting Breast unit and patients' homes.

Participants 39 women with breast cancer.

Main outcome measure Patients' reports of doctors'

characteristics or behaviour that they valued or deprecated.

Results Patients were not primarily concerned with doctors' communication skills. Instead they emphasised doctors' enduring characteristics. Specifically, they valued doctors whom they believed were technically expert, had formed individual relationships with them, and respected them. They therefore valued forms of communication that are currently not emphasised in training and research and did not intrinsically value others that are currently thought important, including provision of information and choice.

Conclusions Women with breast cancer seek to regard their doctors as attachment figures who will care for them. They seek communication that does not compromise this view and that enhances confidence that they are cared for. Testing and elaborating our analysis will help to focus communication research and teaching on what patients need rather than on what professionals think they need.
\end{abstract}

\section{Introduction}

Doctors often communicate poorly with patients who have cancer, so that diagnosis is unnecessarily traumatic and patients do not receive the help they need to understand treatment options. ${ }^{12}$ Communication skills can be enhanced by training, with consequent improvement in patients' satisfaction and wellbeing. ${ }^{34}$ Nevertheless, enhanced communication skills do not always improve patients' experience. ${ }^{5}$

Skills currently targeted by training in communication are diverse and often unclear. $^{6}$ They have been influenced particularly by ideas arising from patient centred medicine, psychotherapeutic communication, informed consent, and shared decision making. ${ }^{7}$ Clinicians are therefore encouraged to provide as much information as possible, to offer choice and to discuss emotional issues, and extensive research assesses how well they do. ${ }^{8}$ Yet professionals' and patients' views as to what is good communication about cancer can diverge, and patients' satisfaction with a consultation is not always related to observer ratings of the formal quality of clinicians' communication. ${ }^{5} 10$ Future development of communication training for clinicians specialising in cancer should be informed by systematic research into patients' perspectives. We aimed to describe what women with breast cancer sought from communication with their clinicians. When this aim was addressed by using a structured questionnaire, findings concurred with the current emphasis on information, choice, and emotional discussion. ${ }^{11}$ As this approach risked perpetuating existing ideas-patients can express views only on topics raised by researchers-we adopted a qualitative approach. We examined clinicians' communication according to how patients experienced it.

\section{Methods}

We selected women with primary breast cancer consecutively from surgery and oncology clinics to include a range of stages in treatment from histological diagnosis after surgery to follow up at two years. Patients were excluded if they had acute distress, cognitive impairment, or insufficient English.

The researcher asked patients identified by clinicians for consent to a study of what is important to them about doctors' communication. By grounding interviews in recent consultation, we sought to minimise generalised or idealised accounts. After pilot interviews with six patients (data not shown), we audiotaped clinical consultations and semistructured interviews in the patient's home 1-5 days later. Surgical and oncology consultations at the same clinic visit were both recorded. The interviewer (EB) explained that she was a researcher, independent of the clinical team. Informed by the transcript of consultation, relevant parts of which were recounted to the patient, EB prompted patients to describe aspects of communication that they valued or deprecated in that consultation and with all doctors involved in their care. She avoided closed questions, using open questions, prompts, and reflection. To probe patients' preferences, she prompted them to contrast communication or consultations that they had valued or disliked. The interview's pace, sequencing, and duration (20-90 minutes) depended on the patient.

Transcripts were read by EB and PS to identify sections or features to inform the interview. Initially we emphasised turning points in the consultation: in particular information on prognosis or treatment. Later we focused on aspects that could test the developing analysis; in particular where doctors' communication deviated from current expectations (for example, religious allusions) and where patients' accounts had seemed discrepant with the consultation (for example, patients reported being "given the facts" when little information was conveyed).

Using a constant comparison approach, anonymised interview transcripts were analysed inductively, in parallel with the interviews. Recurrent patterns were identified and tested by cycling between data and analysis and discussion among authors. We judged the developing analysis according to its coherence and theoretical validity (whereby conclusions should connect 
Details of patients and doctors whose consultations were recorded. Values are numbers of participants unless stated otherwise

\begin{tabular}{|c|c|}
\hline Characteristics & No of participants \\
\hline \multicolumn{2}{|l|}{ Patients } \\
\hline Number & 39 \\
\hline Median age (range) & $54(34-84)$ \\
\hline \multicolumn{2}{|l|}{ Most recent occupation: } \\
\hline None & 12 \\
\hline Manual & 3 \\
\hline Clerical or shop worker & 15 \\
\hline Professional & 9 \\
\hline \multicolumn{2}{|l|}{ Stage of cancer: } \\
\hline I & 5 \\
\hline IIA & 15 \\
\hline IIB & 9 \\
\hline IIIA & 5 \\
\hline IIIB & 4 \\
\hline Not known & 1 \\
\hline \multicolumn{2}{|l|}{ Surgical treatments for breast cancer: } \\
\hline Wide local excision & 13 \\
\hline Mastectomy & 26 \\
\hline Breast reconstruction & 9 \\
\hline \multicolumn{2}{|l|}{ Adjuvant treatment for breast cancer: } \\
\hline $\begin{array}{l}\text { Tamoxifen } \\
\end{array}$ & 17 \\
\hline Chemotherapy & 14 \\
\hline Radiotherapy & 10 \\
\hline \multicolumn{2}{|l|}{ Time of interview: } \\
\hline 9-16 days postoperatively & 17 \\
\hline 1-12 months postoperatively & 7 \\
\hline$>12$ months postoperatively & 15 \\
\hline \multicolumn{2}{|l|}{ Consultations recorded: } \\
\hline Surgeon & 31 \\
\hline Oncologist & 17 \\
\hline \multicolumn{2}{|l|}{ Recorded doctors } \\
\hline \multicolumn{2}{|l|}{ Surgeons: } \\
\hline $\begin{array}{c}\text { Consultants } \\
\end{array}$ & 5 \\
\hline Registrars & 2 \\
\hline $\begin{array}{l}\text { Median No (range) of consultations recorded for } \\
\text { each: }\end{array}$ & $4 \quad(1-8)$ \\
\hline \multicolumn{2}{|l|}{ Oncologists } \\
\hline $\begin{array}{c}\text { Consultants } \\
\end{array}$ & 3 \\
\hline Registrars & 2 \\
\hline $\begin{array}{l}\text { Median No (range) of consultations recorded for } \\
\text { each }\end{array}$ & $2(1-10)$ \\
\hline
\end{tabular}

with theoretical ideas beyond the present study) and catalytic validity-that is, its potential to influence practice and research. ${ }^{12}$ The study ended when findings were unimproved by further interviews or analysis. The transcripts showed the range and commonality of content of each finding.

\section{Results}

Four patients declined to participate; 39 consented and were recorded in consultation with 12 doctors. The table summarises the details of the patients and doctors.

Patients did not focus on doctors' communication. Instead, they emphasised doctors' attributes or personality-that the doctor was "the type I want." We therefore organised the analysis around three perceived attributes of doctors that structured the patients' accounts: expertise; caring; and respecting the patient (boxes 1-3).

\section{Expertise}

The dominant concern was the need to trust doctors' expertise: "You feel you could put your life in her hands" (patient 3); "if you

\section{Box 1: Ways in which doctors could communicate} expertise

Demonstrate a tangible skill

"She [oncologist] really does give you a good examination" (patient 22)

Display confidence and efficiency and make things happen "He seems to move pretty quickly, get everything organised ... and that's the general feeling that things are going OK" (patient 8)

Answer all questions without hesitation

"She answers questions with no hesitation ... so quickly you felt she was telling you the truth" (patient 9)

Do not mislead

"He lied, or fibbed, or spared your feelings, about me mum [who died from breast cancer previously]. I lost all faith in what everybody was telling me then" (patient 9).

Tell the patient you will be open

"He did say to me before the operation ... what we know you will

know, there's nothing we'll keep from you ... I just think he was absolutely fantastic" (patient 10)

Avoid telling patients things they do not want to know about

"I don't want to know whether I'm cured or not" (patient 21)

Explain ways in which patient's disease is not as bad as it might

have been

"He explained how lucky I was" (patient 10)

asked me what the most important thing was, it's confidence in their ability" (patient 9).

Expertise was communicated by being a doctor, and by being efficient, acclaimed, or frank. Being a doctor was often sufficient, because "they know all about you" (patient 18). Confidence was enhanced by knowing the doctor's reputation-for example, that "he's one of today's trendsetters" (patient 4), "specialises in breast cancer" (patient 28), or is "the top in his field" (patient 1). This could readily be communicated by other patients or staff: "From what [nurse] tells me this morning, he'll do everything he can" (patient 4). Tangible evidence of skill inspired more general confidence. Although this favoured surgeons, whose stitching patients commended, other demonstrations of skill or efficiency were also effective.

Box 2: Ways in which doctors could communicate relationship with patients

Help patients feel special

"That's how he made me feel ... I wasn't just a patient. This is about you ... because he said to me the first time we went, he said there's a guardian angel sitting on your shoulder" (patient 10) Talk briefly about something other than cancer

"Being prepared to take that couple of minutes out, you know to talk about something else, it just makes you feel more like a person" (patient 8 )

Display natural idiosyncrasies-for example, sensitive use of humour, nationality, religion, gender

"He was marvellous. He said 'listen, for all our technology, we don't know everything.'... He said 'Do you believe in God?' So I said 'Yes', and he said 'Well then, leave things in the hands of God.' And it was so different from the other fellow who'd practically said he was" (patient 21)

Do something for patient that seems not to be dictated by role

"He made the time to come out and see me out of his schedule ... and when I got to the ward for 8 o'clock on the Friday he was there waiting to speak to me again ... Now he didn't have to do this ... He took the time out, and I just think, out of a schedule like his ... I just think it was what I needed" (patient 15). 
Patients freely linked trust to feeling that they had been "given the facts" (patient 8). They welcomed doctors simply telling them that they would be open. However, other comments indicated that patients did not want to be given as much information as possible. They valued doctors' frankness only in relation to information that they sought. Indeed, several complained of being "over-informed." Desire for information was also shaped by wanting to be left "on a positive note" (patient 1) so that "I felt quite hopeful when she'd [oncologist] finished" (patient 31). Doctors had often achieved this by explaining how the cancer was not as bad as it might have been.

\section{Relationship with patient}

Patients wanted "a relationship" with the doctor-that is, that the doctor and patient see each other as individuals.

\section{Seeing the patient as an individual}

The perception of being regarded as an individual was communicated in several ways. Non-verbal cues included eye contact, smiling, touching, and vocal intonation. The simplest verbal strategy, albeit rare, was for the doctor to tell the patient that she was special (see box 2). The most common strategy, however, was brief conversation unrelated to disease.

\section{Being an individual}

Several patients liked their doctor "as a person" (patient 3). Some attributed likeability to characteristics such as sex or nationality. Female doctors were valued because "women enjoy the natter ... a female doctor'll enjoy the consultation more than a man will ... it's a sisterhood" (patient 22), others "because they're Irish, they've just got that openness to take in people's problems" (patient 28). Idiosyncratic behaviour also identified doctors as likeable individuals. No patient criticised doctors' humour, and several valued it: "It takes the pressure out of the situation" (patient 3). Similarly, no patient disliked doctors' occasional religious allusions, and two valued them (see box 2).

The most striking way a doctor could be seen as an individual was by doing something that "he didn't have to do" (patient 28). The value of perceived departure from role was magnified by the doctor's status: "For a busy surgeon like that to take the time to sit you down and reassure you, it's a rare thing, a professor as well, so it must be part of their personality" (patient 28).

\section{Respecting the patient}

Patients sought to feel respected as "part of the team, fighting the same battle" (patient 22) and to be afforded the dignity and rights associated with being "a human being, somebody who has an opinion" (patient 15). This need was clearest when patients described fearing "being a bother" (patient 26): "You don't want to ... upset your consultant ... obviously if he picks up that you're

\section{Box 3: Ways in which doctors could communicate} respect for patients

Consult at eye level, when patient is fully dressed

"They should interview you in an office ... fully dressed ... like you were going for a job" (patient 21)

Match language to patient's expectations

"She was very ordinary, you know. She didn't like blind you with science" (patient 26)

"She doesn't talk down to you" (patient 28)

Give patient the "option" to agree to decisions

"I didn't have to have it [chemotherapy]. It was up to me" (patient 26) arrogant, he can treat you anyway he wants ... he has the power" (patient 6). In interviews, these fears arose particularly when patients explained reluctance to disclose distress or to ask questions. Doctors communicated respect in two main ways.

\section{Addressing the patient on the same level}

The simplest way doctors communicated respect was by sitting down "at eye-level" (patient 24). Patients also wanted doctors' language to be on a level with their intelligence, but this meant different language for different patients (see box 3).

\section{Giving the patient the "option"}

Patients consistently valued being "given the option" (patient 6). However, the option did not equate to choice as this is usually understood. No patient described a process of decision making in which they considered, and selected from, presented options. They had concurred with clinicians' recommendations. Moreover, several explicitly rejected responsibility for decisions-" "they both said it's your decision ... but I needed to be told" (patient 25)-giving two reasons. Firstly, "we've not got the education, that's their job" (patient 11). Secondly, responsibility was incompatible with trust: "When I went with the lump, they said to me, do you want to go to the hospital ... I could have turned round and said no I don't want to go. That always sticks in me mind ... didn't have a lot of faith in them after that" (patient 26).

\section{Responses to poor communication}

Trust in doctor's expertise was irretrievable when patients thought that they had been misled (see box 1). In other instances when patients disliked communication, they interpreted it in ways that did not challenge their confidence in the doctor's characteristics (box 4).

\section{Discussion}

Patients with breast cancer did not think about their doctors according to whether they "communicated well." Instead they were concerned with whether their doctors had expertise they could trust, had a personal relationship with them, and respected their status as autonomous individuals.

\section{Box 4: Ways that patients' preserved their positive view} of doctors' attributes

Distinguish the person from his or her behaviour

"He doesn't really have much of a bedside manner, he's quite, he comes across as quite cold, I'm sure he isn't" (patient 9)

Attribute to doctor's role rather than personality

"She [surgeon] didn't sit down did she? ... [Oncologist] is a bit calmer when I go to see her. She's always sat down, but maybe she doesn't have as much worry as [surgeon]" (patient 23)

Regard communication problems as aspects of doctor's individuality

"By the time I came to meet him the third time, I'd got used to

his way ...I was in tune with him" (patient 1 )

Attribute good intentions

"The way he did it was probably very good. I did think ... he was a bit curt, but I think when you've been diagnosed with something so serious, he just comes to the point and tells you straight, because that is really what you want" (patient 4)

Prioritise doctors' expertise

"He was very brusque and to the point, you know, and it was a bit shaking really, it wasn't nice. But he was a good surgeon" (patient 13) 
It is understandable that patients seek these characteristics. When individuals feel vulnerable in the face of major threats, they seek attachment figures to help them feel safe. ${ }^{13-15}$ Only a doctor who was believed to be expert, to value the patient as an equal, and to be committed to the patient in a unique relationship could fulfil this role. The starting point for study and training of clinical communication should therefore be patients' vulnerability and dependence on doctors. From this perspective, patients' perception of the relationship with their clinicians arises from their attachment needs and is not, as currently widely assumed, solely built by communication. ${ }^{7}$ Indeed, patients in our study often discounted poor communication in ways that preserved their confidence in doctors' attributes. The further significance of our study is to show that patients are not well served by some forms of communication that are currently thought important, including information, choice, and emotional discussion. ${ }^{6-8}$ Moreover, some of the types of communication that they sought are mainly neglected by teaching and research (see boxes 1-3).

\section{Expertise}

Trust in doctors' expertise was our patients' main concern, as it was for patients with cancer in previous studies, yet this is currently not explicitly emphasised by communication research and teaching. ${ }^{6-8} 1016$ It was not difficult for doctors to communicate expertise. Being a doctor was enough for many patients, but confidence was increased when doctors displayed efficiency and technical skill, such as physical examination or neat stitching, or were acclaimed by staff or patients.

Being frank also enhanced trust, but what patients sought diverged from the current emphasis on providing information. It was a function not of amount of information but of the nature of information and manner of presentation. Patients trusted doctors who answered their questions without hesitation and distrusted doctors whom they suspected of not answering honestly, but many wanted not to be informed about aspects of prognosis and to be "left on a positive note." Reports that patients with cancer want to have as much information as possible present a dilemma because information that is potentially communicable is infinite. ${ }^{17} \mathrm{~A}$ resolution is to recognise that, contrary to usual assumptions, patients do not generally seek information to be better informed but for other reasons. ${ }^{14}{ }^{15} \mathrm{We}$ suggest that patients in our study sought information primarily to maintain hope and trust, a view that contrasts with the suggestion that patients' need for hope and trust constrain their desire for information. ${ }^{18}$

\section{Caring relationship}

That patients with cancer want a relationship with their doctors is already known. ${ }^{16}{ }^{19}{ }^{20}$ However, contrary to currently influential views, patients did not seek relationships based on communication about emotional issues. Instead, they wanted doctors who were individuals and who regarded them as individuals. The value that patients therefore attached to doctors' actions that they "didn't have to do" and to idiosyncratic demonstrations of individuality indicates a challenge for communication training: to reconcile a model of skills that can be learned and applied by all doctors, with patients' wish to experience a genuine and unique relationship.

\section{Respect}

In valuing being given the option rather than choice, patients diverged from the currently influential professional emphasis on patient empowerment and shared decision making, which persists despite previous evidence that many patients prefer to

\section{What is already known on this topic}

Good communication is central to clinical care of women with breast cancer

Training in communication can improve clinical care but does not always improve patients' experience of care

Future development of communication training should be informed by knowledge of what patients seek from clinical communication

\section{What this study adds}

Patients are more concerned with doctors' enduring qualities than with their communication skills

Patients want to know that their doctors have expertise, have a unique relationship with them, and respect their autonomy

Forms of communication that convey these qualities differ from those currently emphasised in communication training and research

be directed about treatment rather than given choice. ${ }^{7172122}$ In wanting the option, patients identified a role for surgeons that equated neither to direction nor choice but meant respecting patients' autonomy. Fallowfield and coworkers found that women with breast cancer treated by surgeons who normally offered choice of treatment became less distressed than those treated by surgeons who denied choice, but they showed that this occurred even in patients who, because of the nature of their tumour, could not be offered choice. ${ }^{23}$ Perhaps the surgeons routinely communicated respect, and their offer of choice where possible was merely one way in which they did this.

This study's contribution is not just to show that patients with breast cancer seek trust, care, and respect. These needs have been identified before, although they are still often neglected in practice. Indeed, convergence with that evidence shows that our study is more generally applicable than to our specific sample. Our findings depart most from current knowledge and assumptions in two ways: by showing how clinical communication can deliver or deny these needs and by showing that aspects of communication currently considered as ends in themselves, such as providing information and offering choice, should be considered from the perspective of the function that they have for patients. Testing and elaborating our analysis will help to focus communication research and teaching on what patients need rather than on what professionals think they need. Taking this direction promises to conflict with the current emphasis on regarding patients as partners in care. It means not returning to medical paternalism but developing a model of clinical communication in which patients' need to feel safe in a caring relationship with a trusted expert is central.

We thank the participation of the anonymous patients and clinicians and Sarah Peters and Fiona Lobban for comments on a draft of this manuscript. Contributors: PS, EB, and CH designed the study. EB collected the data. PS and EB led analysis, to which $\mathrm{CH}$ contributed. PS led the writing of the paper and EB and CH contributed. PS and EB will act as guarantors for the paper. The guarantor accepts full responsibility for the conduct of the study, had access to the data, and controlled the decision to publish.

Funding: This work was not externally funded. EBW was funded by Gloucestershire Local Education Authority for the intercalated year during which she collected these data. 
Competing interests: None declared.

Ethical approval: This study was approved by Liverpool research ethics committee.

1 Maguire P. Improving communication with cancer patients. Eur J Cancer 1999;35:2058 65 .

2 Fallowfield L, Jenkins V. Effective communication skills are the key to good cancer care. Eur J Cancer 1999;35:1592-7.

3 Fallowfield L, Jenkins V, Farewell V, Saul J, Duffy A, Eves R. Efficacy of a Cancer Research UK communication skills training model for oncologists: a randomised conrolled trial. Lancet 2002;359:650-6.

4 Rutter DR, Iconomou G, Quine L. Doctor-patient communication and outcome in cancer patients: an intervention. Psychol Health 1996;12:57-71.

5 Hulsman RL, Ros WJG, Winnubst JAM, Bensing JM. The effectiveness of a computerassisted instruction programme on communication skills of medical specialists in oncology. Med Educ 2002;36:125-34.

6 Cegala DJ, Broz SL. Physician communication skills training: a review of theoretical backgrounds, objectives and skills. Med Educ 2002;36:1004-16.

Makoul G. Essential elements of communication in medical encounters: the Kalamazoo consensus statement. Acad Med 2001;76:390-3.

8 Tattersall MHN, Butow PN, Clayton JM. Insights from cancer patient communication Tattersall MHN, Butow PN, Clayton JM. Insights from
research. Hematol Oncol Clin North Am 2002;16:731-43.

9 Larsson G, Peterson VW, Lampic C, Von Essen L, Per-Olow S. Cancer patient and staff ratings of the importance of caring behaviours and their relations to patient anxiety and depression. J Adv Nurs 1998;27:855-64.

10 Schofield PE, Beeney LJ, Thompson JF, Butow PN, Tattersall MHN, Dunn SM. Hearing the bad news of a cancer diagnosis: the Australian melanoma patient's perspective. Ann Oncol 2001;12:365-71.

11 Rankin N, Newell S, Sanson-Fisher R, Girgis A. Consumer participation in the development of psychosocial clinical practice guidelines: opinions of women with breast cancer. Fur J Cancer Care 2000:9:97-104

12 Guba EG, Lincoln YS. Fourth generation evaluation. Newbury Park, CA: Sage, 1989

13 Bowlby J. The making and breaking of affectional bonds. London: Routledge, 1998.

14 Salander P. Bad news from the patient's perspective: an analysis of the written Salander P. Bad news from the patient's perspective: an analysis of
narratives of newly diagnosed cancer patients. Soc Sci Med 2002;55:721-32.
15 Salander P, Bergenheim T, Henriksson R. The creation of protection and hope in patients with malignant brain tumours. Soc Sci Med 1996;42:985-96.

16 Henman MJ, Butow PN, Brown RF, Boyle F, Tattersall MHN. Lay constructions of decision-making in cancer. Psycho-oncol 2002;11:295-306.

17 Jefford M, Tattersall MHN. Informing and involving cancer patients in their own care. Lancet Oncol 2002;3:629-37.

18 Leydon GM, Boulton M, Moynihan C, Jones A, Mossman J, Boudioni M, et al. Cancer patients' information needs and information seeking behaviour: in depth interview study. BMJ 2000;320:909-13.

19 McWilliam CL, Belle Brown J, Stewart M. Breast cancer patients' experiences of patient-doctor communication: a working relationship. Pat Educ Counseling 2000:39:191-204

20 Butow PN, Dowsett S, Hagerty R, Tattersall MHN. Communicating prognosis to patients with metastatic disease: what do they really want to know? Support Care Cancer 2002;10:161-8.

21 Fallowfield LJ. Offering choice of surgical treatment to women with breast cancer. Patient Educ Couns 1997;30:209-14.

22 De Haes H, Koedoot N. Patient centred decision making in palliative cancer treatment: a world of paradoxes. Patient Educ Couns 2003;50:43-9.

23 Fallowfield LJ, Hall A, Maguire GP, Baum M. Psychological outcomes of different treatment policies in women with early breast cancer outside a clinical trial. BMJ 1990;301:575-80.

(Accepted 29 January 2004)

doi $10.1136 /$ bmj.38046.771308.7C

Royal Liverpool University Hospital, Liverpool L7 8XP

Emma Burkitt Wright senior house officer in medicine

Linda McCartney Centre, Royal Liverpool University Hospital

Christopher Holcombe consultant surgeon

Department of Clinical Psychology, University of Liverpool, Liverpool L69 3GB

Peter Salmon professor of clinical psychology

Correspondence to: P Salmon psalmon@liv.ac.uk 